\title{
A Practical Model for Inbound Container Distribution Organization in Rail-Water Transhipping Terminal
}

\author{
Jiahao Zhao, ${ }^{1}$ Xiaoning Zhu ${ }^{D},{ }^{1}$ Yong Liu, ${ }^{2}$ Li Wang, ${ }^{1}$ and Baicheng Yan ${ }^{1}$ \\ ${ }^{1}$ School of Traffic and Transportation, Beijing Jiaotong University, Beijing 100044, China \\ ${ }^{2}$ Shenzhen Urban Transportation Planning Center, Shenzhen, Guangdong Province 518021, China \\ Correspondence should be addressed to Xiaoning Zhu; xnzhu@bjtu.edu.cn
}

Received 19 October 2017; Revised 7 February 2018; Accepted 4 March 2018; Published 5 April 2018

Academic Editor: Manuel Pineda-Sanchez

Copyright (c) 2018 Jiahao Zhao et al. This is an open access article distributed under the Creative Commons Attribution License, which permits unrestricted use, distribution, and reproduction in any medium, provided the original work is properly cited.

\begin{abstract}
Rail-water transportation is a crucial component of intermodal transportation system. Effective operation of rail-water intermodal transportation requires not only railway network and advanced handling equipment, but also scientific and reasonable transportation organization. In this paper, we first briefly introduced the coordination area and related concepts. Then an inbound container distribution organization model (ICDOM) was established taking into account many factors such as transhipping capacity, network capacity, and importance of containers, in order to minimize the total container-hours in the coordination area, which reflects the efficiency of inbound container distribution organization. Additionally, a genetic algorithm (GA) was developed and the optimization results were evaluated, which showed that both of the model and the algorithm were effective.
\end{abstract}

\section{Introduction}

Rail-water intermodal transportation is an important component of intermodal transportation system and links to the construction of an integrated transportation system, which is recognized by the society for its efficient, economical, and environmentally friendly operational manner. In Europe, the intermodal freight transportation has been considered as a potential competitor to road freight transportation in medium-to-long distance corridors [1]. In China, railwater intermodal transportation has become an important part of the national development strategy deployment. Railwater intermodal transportation infrastructure construction has made great progress, and the container transportation network has been gradually improved. Nevertheless, the railwater intermodal transportation could not be an efficient operation until the concentration and distribution organization of the containers are coordinated and the relationship between container liner ships and container trains is clear. Therefore, how to strengthen rail-water intermodal transportation and promote the integration of multiple container transportation processes has become an urgent task which needs to be tackled.
The concept of intermodal transportation has been discussed intensively since few years ago. Macharis and Bontekoning argued that intermodal freight transportation was going to be emerging as a new transportation research field and gave a general review of operational research models used in this field and in modelling problems [2]. After that, the intermodal transportation has received more considerable attention.

Considering the intermodal transportation organization is to optimize train distribution organization. Wei analyzed the characteristics of container intermodal transportation organization and established the models based on the coordination management [3]. Qi further studied the multikey factors for building an optimum model of railwater which combined container transportation organization based on the inland-port transferring railway hub container transportation system [4]. Li et al. investigated intermodal transportation planning problems in deep-sea and inland terminals to seize the key characteristics of intermodal transportation [5]. Some optimization models regarding rail-truck intermodal shipments were proposed [6-8]. Manish et al. proposed a biobjective optimization framework for routing rail-truck intermodal shipments. Phan and Kim created a 


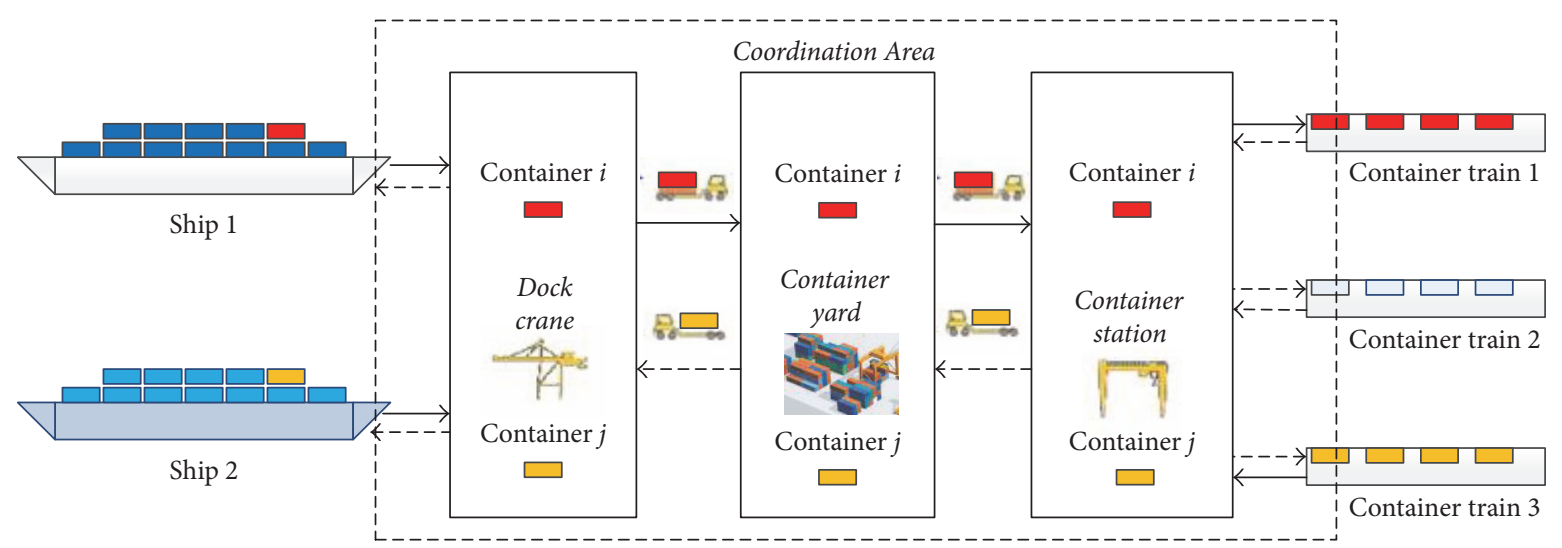

FIGURE 1: Coordination area of distribution organization in rail-yard-water mode terminal.

mathematical model to optimize dispatching schedules for trucks.

The railway transportation organization has been made to optimize the train scheme [9-15]. Yan studied the assignment problem of transportation resource in railway container skeleton network from three aspects which were the pattern of train organization, the frequency of trains, and the distribution of containers [9]. Two optimization models about the railway multimodal cargo container transportation were built based on different destinations [11]. Kuo et al. implemented a train slot selection model in order to determine freight train timetables [12]. Chen et al. proposed a definition of resilience and built an integer programming model to give a quantitative measurement of resilience [15].

In consideration of the coordination between the container liner ships and trains, container terminal is a key part in the study [16-21]. Wu et al. studied the optimization of yard operations and developed a linear mixed integer programming model for scheduling different types of equipment and for planning the storage strategy in an integrated way [16]. Hu et al. used a time-space graph and a tabu search algorithm for interterminal container transportation [18]. Ku and Arthanari proposed a stochastic dynamic programming model to calculate the minimum expected number of reshuffles for a stack of containers which all have departure time windows [20].

Although many works have been done for intermodal transportation organization, terminal operations organization, and transportation path planning, there are still some deficiencies as follows:

(1) Most transportation optimization models only consider the factors in the development of a single transportation mode, but do not take into account other modes in the intermodal transportation system of transportation planning. The effects of other transportation modes are treated as random variables.

(2) Unlike other countries, China has a huge transport demand, while its transportation capacity is very tense. However, only few studies have addressed the issue of organization optimization for intermodal transportation from the perspective of capacity coordination.
The objective of this paper is to minimize the total container-hours in the coordination area. The contributions of this paper are summarized as follows. This paper analyzes the factors affecting the inbound container distribution organization and establishes an inbound container distribution organization model (ICDOM) by taking into account the operating capacity and resource constraints. Additionally, a genetic algorithm is improved to deal with the model. At last, the optimization results show that the model and algorithm are effective.

\section{Inbound Container Distribution Organization Model}

2.1. Problem Description. The inbound container distribution organization in rail-water transhipping terminal refers to a complete series of processes involving unloading the container liner ships, handling operations of the storage yard, and loading the container trains. During the operation processes, plenty of equipment pieces such as bridge cranes, container trucks, gantry cranes, and reach stackers are used to improve the efficiency. The requirements and characteristics in different situations will result in different organization and operation. Therefore, the most widely used "rail-yard-water" mode is chosen to be studied.

As shown in Figure 1, we can easily know the process of inbound container distribution organization in the "railyard-water" mode. After the arrival of the container liner ships, the first operation is to unload the ships. Then the containers will be transported to the container yard or to the container station directly by container truck or AGV. When the stored containers in the yard need to be transported to the container station, the container trucks and AGV will take them to the station. When all the operation is completed in container station, the container train would depart from the station on the basis of the distribution organization.

Different from the traditional freight train formation plan, the operation of rail-water container trains should depend on the time of container liner ships and the capacity of each operation to some extent. The economic benefits and timeliness should be considered to achieve the optimization 
of inbound container distribution organization. Therefore, the dock crane area, container yard area, and container station area, in the distribution organization, are defined as the coordination area, which is already marked in the Figure 1, to analyze the key elements of distribution organization.

2.2. Basic Assumptions. The container liner ships transportation process has many influencing factors, including a wide range of time and space complexity. To facilitate the model formulation, several assumptions are made and explained in this section.

Assumption 1. The organization of container liner ships transportation has periodic characteristics, and the cycle is much longer than that of trains. To achieve the uniformity of planning, the basic unit time of the transportation organization will be a certain period of time.

Assumption 2. In a certain period of time, the arrival time of container liner ships is known. The amounts of containers and their terminals are certain because the information of containers on the ship will be released to the port and the station in advance.

Assumption 3. The container information and the demand for containers and vehicles will be known in advance. As a result, this paper assumes that there would be enough empty containers and vehicles.

2.3. Symbol Notations. Some symbolic notations used in inbound container distribution organization model are defined as follows. The following are the necessary parameters:

$T$ : the total number of unit time intervals during the planning cycle

$i$ : the number of the container liner ships, $i \in I, I=$ $\{i / i=0,1, \ldots, m\}$, where $m$ is the total number of container liner ships during the planning cycle

$j$ : the number of the freight trains, $j \in J, J=\{j / j=$ $0,1, \ldots, n\}$, where $n$ is the total number of container trains during the planning cycle

$d$ : the number of the inbound container transportation directions, $d \in D, D=\{d / d=1, \ldots, p\}$, where $p$ is the total number of inbound container transportation directions during the planning cycle

$T_{f i}$ : the finish time of unloading container liner ship $i$

$T_{s j}$ : the start time of loading container train $j$

$T_{f j}$ : the finish time of loading container train $j$ and the departure time of train $j$

$\mathrm{NS}_{i}$ : the total number of distribution containers on container liner ship $i$

$\mathrm{NS}_{i d}$ : the total number of direction $d$ containers on container liner ship $i$

$\mathrm{NT}_{j}$ : the total number of containers on container trains $j$
$\mathrm{NT}_{\text {max }}$ : the maximum number of containers on a container train

$\mathrm{NT}_{\min }$ : the minimum number of containers on a container train

$\mathrm{NY}_{\text {max }}$ : the maximum number of containers allowed in the yard

$t_{\text {trs }}$ : the average time of moving a container from the quay to the railway handling line

$t_{\mathrm{lo}}$ : the average time of loading a container to liner train, $t_{\mathrm{lo}}=\left(T_{d j f}-T_{d j s}\right) / \mathrm{NT}_{j}$

$M$ : a large integer value

$N_{0}$ : the total number of remaining containers during the previous planning cycle

$k$ : the number of receiving-departure operations, $k \in$ $K, K=\{k / k=0,1, \ldots, q\}, q=m+n$, where $q$ is the total number of receiving-departure operations during the planning cycle

$T_{k}$ : the receiving-departure moment of liner ships $T_{f i}$ and trains $T_{d j f}$ in the order of time during the planning cycle, $T_{k}=\min \left(T_{f i}, T_{f j}\right), k \in K, i \in I, j \in$ $J, T_{0}=0, T_{k}=T$

$t_{f k}$ : the $k$ th receiving-departure time interval $t_{f k}=$ $T_{k+1}-T_{k}, t_{f 1}=T_{1}-T_{0}, t_{\mathrm{fk}}=T_{t}-T_{N_{k}}$

$N_{i d}^{t}$ : total number of direction $d$ containers on container liner ship $i$ when $T_{f i}$ is $t$

$N_{i}^{t}$ : total number of containers on container liner ship $i$ when $T_{f i}$ is $t, N_{i}^{t}=\sum_{d=1}^{p} N_{i d}^{t}$

$N_{j d}^{t}$ : total number of direction $d$ containers on container liner train $j$ when $\mathrm{T}_{f j}$ is $t$

$N_{j}^{t}$ : total number of containers on container liner train $j$ when $\mathrm{T}_{f j}$ is $t, N_{j d}^{t}=\sum_{d=1}^{p} N_{j d}^{t}$.

The following are the decision variables for the container:

$\operatorname{Dec}_{j}^{t}$ : when the container train is $j$ and the departure time is $t, \operatorname{Dec}_{j}^{t}=1$; else $\operatorname{Dec}_{j}^{t}=0$

$\operatorname{Dec}_{j d}^{t}$ : when the container train is $j$, the inbound container transportation direction is $d$ and the departure time is $t, \operatorname{Dec}_{j d}^{t}=1$; else $\operatorname{Dec}_{j d}^{t}=0$

$\operatorname{Imp}_{i}^{j}$ : when the container liner ship is $i$ and the container train is $j, \operatorname{Imp}_{i}^{j}=1$; else $\operatorname{Imp}_{i}^{j}=0$

$\operatorname{Imp}_{i d}^{j}$ : when the container liner ship is $i$, the inbound container transportation direction is $d$ and the container train is $j, \operatorname{Imp}_{i d}^{j}=1$; else $\operatorname{Imp}_{i d}^{j}=0$.

2.4. Objective Function. The whole time of inbound container distribution organization is represented by the total time from unloading the container liner ship to loading the container train. And the whole displacement is represented by the distance from the container terminal to the railway handling operation line. 


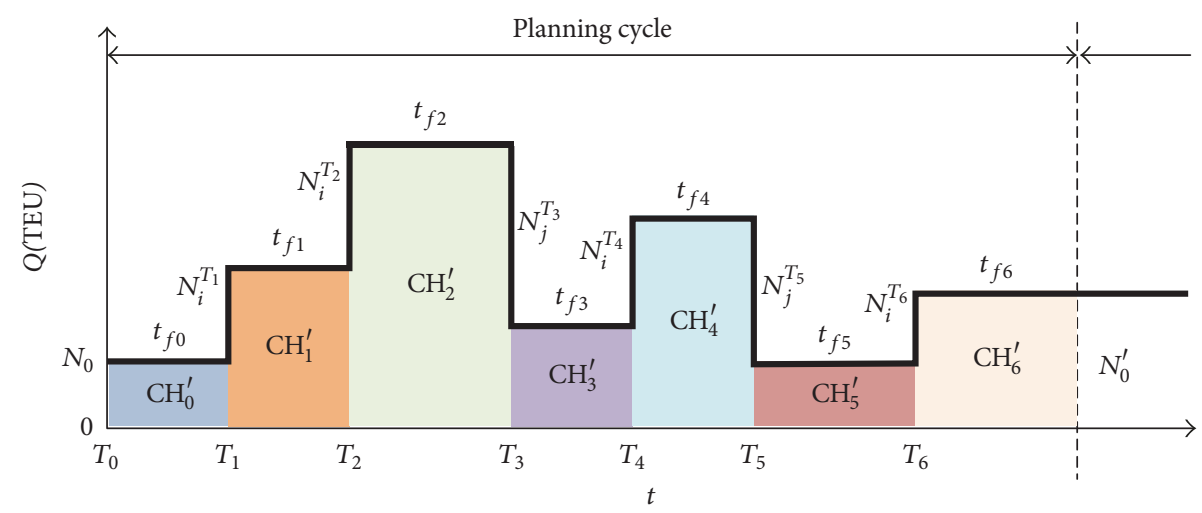

FIgURE 2: Schematic diagram of calculation on total container-hours in coordination area.

Therefore, the capacity of the container distribution organization in rail-water transhipping terminal can be described by total container-hours (one container-hour equivalent to a container in the coordination area for an hour) in the coordination area which is involved in the rail-water intermodal transportation during the planning cycle. The shorter time for the containers in the coordination area contributes to the faster container transhipping as well as the higher efficiency of inbound container distribution organization between liner ships and trains. A schematic diagram of calculation on total container-hours in coordination area is shown as in Figure 2.

As shown in Figure 2, we can obtain the equations as follows:

$$
\begin{aligned}
\mathrm{CH}_{0}= & \mathrm{CH}_{0}^{\prime}=N_{0} \cdot t_{f 0}=N_{i}^{T_{0}} \cdot t_{f 0}, \\
\mathrm{CH}_{1}= & \mathrm{CH}_{0}^{\prime}+\mathrm{CH}_{1}^{\prime}=N_{i}^{T_{0}} \cdot t_{f 0}+\left(N_{i}^{T_{0}}+N_{i}^{T_{1}}\right) \cdot t_{f 1} \\
= & N_{i}^{T_{0}} \cdot\left(t_{f 0}+t_{f 1}\right)+N_{i}^{T_{1}} \cdot t_{f 1}, \\
\mathrm{CH}_{2}= & \mathrm{CH}_{0}^{\prime}+\mathrm{CH}_{1}^{\prime}+\mathrm{CH}_{2}^{\prime} \\
= & N_{i}^{T_{0}} \cdot t_{f 0}+\left(N_{i}^{T_{0}}+N_{i}^{T_{1}}\right) \cdot t_{f 1} \\
& +\left(N_{i}^{T_{0}}+N_{i}^{T_{1}}+N_{i}^{T_{2}}\right) \cdot t_{f 2} \\
= & N_{i}^{T_{0}} \cdot\left(t_{f 0}+t_{f 1}+t_{f 2}\right)+N_{i}^{T_{1}} \cdot\left(t_{f 1}+t_{f 2}\right) \\
& +N_{i}^{T_{2}} \cdot t_{f 2}, \\
\mathrm{CH}_{3}= & \mathrm{CH}_{0}^{\prime}+\mathrm{CH}_{1}^{\prime}+\mathrm{CH}_{2}^{\prime}+\mathrm{CH}_{3}^{\prime} \\
= & N_{i}^{T_{0}} \cdot t_{f 0}+\left(N_{i}^{T_{0}}+N_{i}^{T_{1}}\right) \cdot t_{f 1} \\
& +\left(N_{i}^{T_{0}}+N_{i}^{T_{1}}+N_{i}^{T_{2}}\right) \cdot t_{f 2} \\
& +\left(N_{i}^{T_{0}}+N_{i}^{T_{1}}+N_{i}^{T_{2}}-N_{j}^{T_{3}}\right) \cdot t_{f 3} \\
= & N_{i}^{T_{0}} \cdot\left(t_{f 0}+t_{f 1}+t_{f 2}+t_{f 3}\right)+N_{i}^{T_{1}} \\
& \cdot\left(t_{f 1}+t_{f 2}+t_{f 3}\right)+N_{i}^{T_{2}} \cdot\left(t_{f 2}+t_{f 3}\right)-N_{j}^{T_{3}} \\
& \cdot t_{f 3} \cdot
\end{aligned}
$$

As a result, the total container-hours in the coordination area are

$$
\begin{gathered}
\mathrm{CH}_{\mathrm{Cal}}=N_{i}^{T_{0}} \cdot\left(t_{f 0}+t_{f 1}+\cdots+t_{f k}\right) \cdot \operatorname{Dec}_{i}^{T_{0}}+N_{i}^{T_{1}} \\
\cdot\left(t_{f 1}+t_{f 2}+\cdots+t_{f k}\right) \cdot \operatorname{Dec}_{i}^{T_{1}}+\cdots+N_{i}^{T_{k}} \cdot t_{f k} \\
\cdot \operatorname{Dec}_{i}^{T_{k}}-\left(N_{j}^{T_{0}} \cdot\left(t_{f 0}+t_{f 1}+\cdots+t_{f k}\right) \cdot \operatorname{Dec}_{j}^{T_{0}}\right. \\
+N_{j}^{T_{1}} \cdot\left(t_{f 1}+t_{f 2}+\cdots+t_{f k}\right) \cdot \operatorname{Dec}_{j}^{T_{1}}+\cdots+N_{j}^{T_{k}} \\
\left.\cdot t_{f k} \cdot \operatorname{Dec}_{j}^{T_{k}}\right)=\sum_{i=1}^{m} \sum_{k=0}^{q} \sum_{d=1}^{p} N_{i d}^{T_{k}} \cdot \sum_{y=k}^{q} t_{f y} \cdot \operatorname{Dec}_{i}^{T_{k}} \\
-\sum_{j=1}^{n} \sum_{k=0}^{q} \sum_{d=1}^{p} N_{j d}^{T_{k}} \cdot \sum_{y=k}^{q} t_{f y} \cdot \operatorname{Dec}_{j}^{T_{k}} .
\end{gathered}
$$

In conclusion, the objective function of this model is denoted by (3), where $\eta_{j}^{T_{k}}$ and $\eta_{j d}^{T_{k}}$ are coefficients to distinguish the importance of the containers.

Objective Function

$=\min ($ the Equivalent total container - hours $)$

$$
\begin{aligned}
& =\mathrm{CH}_{\text {Cycle }}=\sum_{i=1}^{m} \sum_{k=0}^{q} N_{i}^{T_{k}} \cdot \sum_{y=k}^{q} t_{f y} \cdot \operatorname{Dec}_{i}^{T_{k}} \\
& -\sum_{j=1}^{n} \sum_{k=0}^{q} \eta_{j}^{T_{k}} \cdot N_{j}^{T_{k}} \cdot \sum_{y=k}^{q} t_{f y} \cdot \operatorname{Dec}_{j}^{T_{k}}=\sum_{i=1}^{m} \sum_{k=0}^{q} \sum_{d=1}^{p} N_{i d}^{T_{k}} \\
& \cdot \sum_{y=k}^{q} t_{f y} \cdot \operatorname{Dec}_{i}^{T_{k}}-\sum_{j=1}^{n} \sum_{k=0}^{q} \sum_{d=1}^{p} \eta_{j d}^{T_{k}} \cdot N_{j d}^{T_{k}} \cdot \sum_{y=k}^{q} t_{f y} \cdot \operatorname{Dec}_{j}^{T_{k}} \\
= & \left(\sum_{i=1}^{m} \sum_{k=0}^{q} \sum_{d=1}^{p} N_{i d}^{T_{k}} \cdot \operatorname{Dec}_{i d}^{T_{k}}\right. \\
& \left.-\sum_{i=1}^{m} \sum_{j=1}^{n} \sum_{k=0}^{q} \sum_{d=1}^{p} \eta_{j d}^{T_{k}} \cdot \operatorname{Imp}_{i d}^{j} \cdot \operatorname{Dec}_{j d}^{T_{k}}\right) \cdot \sum_{y=k}^{q} t_{f y} .
\end{aligned}
$$


2.5. Model Constraints. Several operational constraints and bounds on inbound container distribution organization are illustrated in this section to ensure the feasibility and the quality of organization.

\subsubsection{Operation Constraints}

(1) Fixed-Axle Constraint. To guarantee the basic benefits of the train and improve the quality of transportation services and market competitiveness, the fixed-axle (fixed-length) constraint of the train must be satisfied, which requires the number of vehicle bottoms (flat cars) above a threshold. According to the current standards of container-specific vehicle bottoms and container technology in China, a containerspecific vehicle bottom can transport two containers (20FT). This means the number of containers is equal to twice the vehicle bottoms. Therefore, the following equations should be satisfied for any time $t \in T$, any container train $j \in J$, and any direction $d \in D$.

$$
\begin{aligned}
\mathrm{NT}_{\min } & \leq \mathrm{NT}_{j} \leq \mathrm{NT}_{\text {max }}, \\
\mathrm{NT}_{j} & =\sum_{i}^{m} \operatorname{Dec}_{j d}^{t} \cdot \mathrm{Imp}_{i d}^{j} .
\end{aligned}
$$

(2) Uniqueness Constraint. There are inbound containers out of the rail-water transhipping terminal when there is a train leaving for the same destination. Every train has only one destination and one departure time because in this problem the container liner trains are point-to-point.

$$
\begin{aligned}
&\left(\operatorname{Dec}_{j d}^{t}-1\right) \cdot \operatorname{Imp}_{i d}^{j}= 0, \\
& \forall t \in T, \forall j \in J, \forall i \in I, \forall d \in D, \\
& \sum_{t}^{T} \sum_{d}^{p} \operatorname{Dec}_{j d}^{t}=1, \quad \forall j \in J .
\end{aligned}
$$

(3) Least Trains Constraint. Containers on a container liner ship will be transported by trains as few as possible.

$$
\sum_{j}^{n} \operatorname{Imp}_{i d}^{j} \leq\left\lceil\frac{\mathrm{NS}_{i d}}{\mathrm{NT}_{\max }}\right\rceil, \quad \forall i \in I, \forall d \in D
$$

\subsubsection{Capacity Constraints}

(1) Yard Storage Capacity Constraint. Due to the uneven distribution of the container liner ships, the number of containers in the yard changes dynamically with the handling operation in the coordination area but cannot exceed the storage capacity of the yard. As a result, the total number of containers in the yard cannot exceed the maximum storage capacity at any time during the planning cycle.

$$
0 \leq N_{0}+\sum_{t=0}^{t} \sum_{i=1}^{m} \sum_{j=1}^{n} \sum_{d=1}^{p}\left(N_{i d}^{t}-\operatorname{Dec}_{j d}^{t} \cdot \operatorname{Imp}_{i d}^{j}\right) \leq C Y_{\text {max }}
$$

$\forall t \in T$.

(2) Handling Operation Capacity Constraint. Once the port construction is completed, the capacity of equipment will be determined. In a certain equipment configuration and scheduling plan, the maximum handling operation capacity is known, which means the minimum time required to load and unload containers can be calculated by the number of containers on the train. In this model, the handling operation capacity is formulated by the minimum departure time interval between two adjacent trains. Therefore, any two adjacent departure time intervals during the planning cycle should not be less than the minimum operating time interval to satisfy the handling operation requirements.

$$
\left(1+M \cdot \sum_{d=1}^{p} \sum_{t=t_{2}}^{t_{1}} \operatorname{Dec}_{j d}^{t}\right) \cdot\left(t_{1} \cdot \operatorname{Dec}_{j_{1} d_{1}}^{t_{1}}-t_{2} \cdot \operatorname{Dec}_{j_{2} d_{2}}^{t_{2}}\right) \geq t_{\mathrm{lo}} \cdot \sum_{i=1}^{m} \operatorname{Dec}_{j d}^{t} \cdot \operatorname{Imp}_{i d}^{j}, \quad \forall j \in J .
$$

(3) Transhipping Capacity Constraint. The capacity of transhipping is formulated by the minimum time from unloading the liner ships to loading trains like handling operation capacity. The time of transhipping containers from the liner ship to the train should not be less than the minimum time required for transhipping.

$$
\begin{aligned}
T_{d j f}-T_{s i} \geq t_{t r s} \cdot \sum_{i=1}^{m} \operatorname{Dec}_{j d}^{t} \cdot \operatorname{Imp}_{i d}^{j} & \\
& \forall d \in D, \forall i \in I, \forall j \in J .
\end{aligned}
$$

2.5.3. Balance Constraints. In this section, the total number of remaining containers during the previous planning cycle can be overlooked, because it is too small to be compared with container amounts during the planning cycle.

(1) Direction Containers Balance Constraint. In the process of inbound container distribution organization, the number of containers on the trains in each direction cannot exceed the total number of containers on the liner ships and from the previous planning cycle in each direction.

$$
N_{0 d}+\sum_{i}^{m} N_{i d}^{t} \geq \sum_{i=1}^{m} \sum_{j=1}^{n} \operatorname{Dec}_{j d}^{t} \cdot \operatorname{Imp}_{i d}^{j}
$$




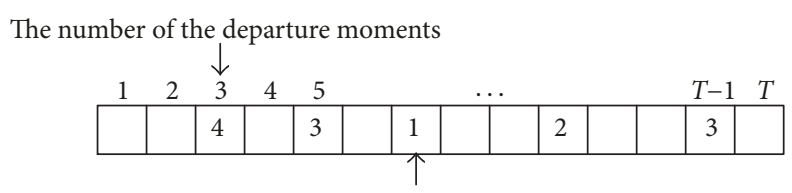

The number of directions

FIGURE 3: Schematic diagram of chromosome 1.

(2) Containers Balance Constraint. The container from the liner ship is assigned to the corresponding train during the planning cycle, because the containers on the trains are transhipped from the liner ships. The total number of containers arriving at the coordination area in rail-water transhipping terminal cannot exceed the total number of containers leaving the area during the planning cycle and remaining from the previous planning cycle.

$$
N_{0}+\sum_{i}^{m} \sum_{d}^{p} N_{i d}^{t} \geq \sum_{i}^{m} \sum_{j}^{n} \sum_{d}^{p} \operatorname{Dec}_{j d}^{t} \cdot \operatorname{Imp}_{i d}^{j}, \quad \forall t \in T
$$

\section{Solution Algorithm}

The analysis of the model shows that the optimization problem of inbound container distribution organization in rail-water transhipping terminal is a nonlinear integer programming problem, which belongs to the NP complete problem. Therefore, an artificial intelligence algorithm, such as genetic algorithm (GA), Tabu Searching (TS) algorithm, and Artificial Neural Network (ANN) algorithm, are selected to solve the model ensuring that the execution time allows the operation managers to obtain a solution within a reasonable amount of time. GA can solve a variety of real-world issues efficiently and effectively, like train sequencing problems [22] and transit network problems [23]. The optimization model of inbound container distribution organization problem in rail-water transhipping terminal is the cooptimization of trains and container distribution organization. Considering the complexity of inbound container distribution organization program under the constraints of time and space resources, this paper uses the large-scale system optimization theory to partition the optimization problem into a two-stage series feedback system and designs a genetic algorithm based on task allocation to solve the model. The detailed algorithmic steps are described as follows.

Step 0 (design of inbound container distribution organization problem). Each distribution organization program corresponds to chromosome 1 , which includes the train number, the departure moment, the direction, and other information, as shown in Figure 3.

Firstly, we create chromosome 1 in which every cell means a time-unit. The length of chromosome 1 is $T$, the total number of unit time intervals during the planning cycle. Secondly, we generate $n$, the total number of container trains during the planning cycle, random directions from $D$, and the inbound container transportation direction and put them into the chromosome 1 cell randomly. After that we get chromosome 1 which involves $n$ no-zero number and $T-n$ zeros. At last we keep the nonzero elements, delete the zero elements, and obtain a chromosome (1).

Step 1 (initial population generation). Population size, the maximum number of iterations, crossover probability, mutation probability, and so on should be given to GA parameters. Then repeat Step 0 until an initial population is generated. Gen $=1$.

Step 2 (fitness calculation). Decode operation on the population and input the liner ships container arrival information to the simulation structure of inbound container distribution organization problem, as shown in Figure 4 . Then the container trains scheme could be obtained and used to calculate the population fitness, which was the inverse of the objective function as shown in

$$
f=\frac{1}{\left(\sum_{i=1}^{m} \sum_{k=0}^{q} \sum_{d=1}^{p} N_{i d}^{T_{k}} \cdot \operatorname{Dec}_{i d}^{T_{k}}-\sum_{i=1}^{m} \sum_{j=1}^{n} \sum_{k=0}^{q} \sum_{d=1}^{p} \eta_{j d}^{T_{k}} \cdot \operatorname{Imp}_{i d}^{j} \cdot \operatorname{Dec}_{j d}^{T_{k}}\right) \cdot \sum_{y=k}^{q} t_{f y}} .
$$

Step 3 (selection operation). The selection operator is mainly to preserve the excellent individuals in the population and copy them to the next population. In this paper, the roulette wheel selection method is applied to realize the random selection of individuals. The best individual preservation rules are used to select better individuals to accelerate the search speed.
Step 4 (crossover operation). Two-point crossover method, which makes the genetic algorithm have the capability of global searching, is used to generate new population. An example is given next. First of all, two parent individuals, chromosome (1) and chromosome (2), are selected. Then two crossover points are selected randomly, which could be continuous or not. At last, they are exchanged to produce two 


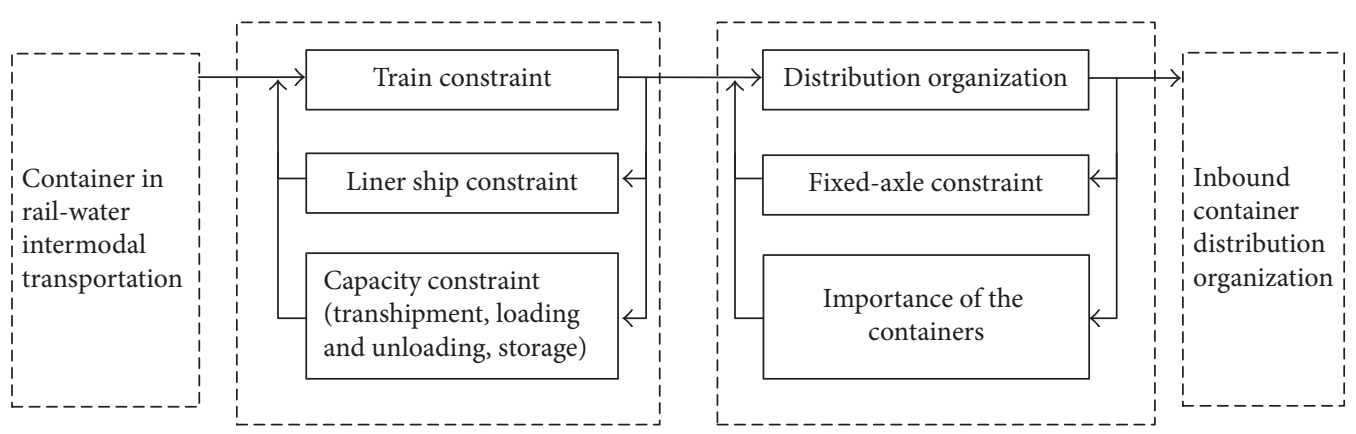

FIgURE 4: The simulation structure of inbound container distribution organization problem.
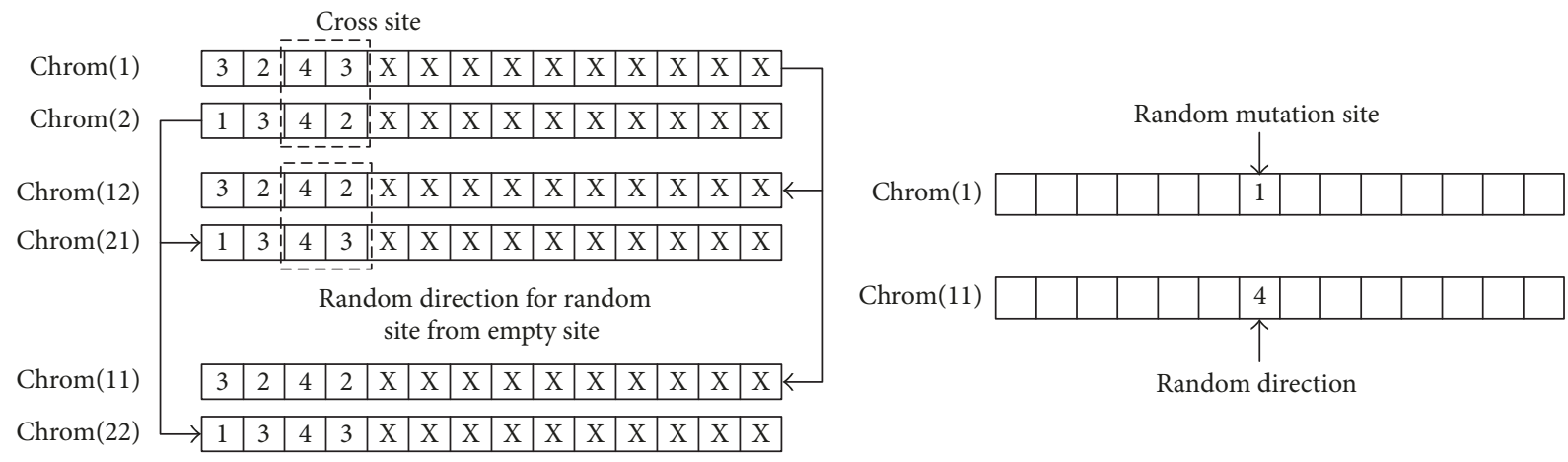

FIGURE 5: Schematic diagram of crossover operation and mutation operation.

new children individuals, chromosome (11) and chromosome (22). The specific operation process is shown in Figure 5.

Step 5 (mutation operation). Mutation operation which allows the acquisition of new genes is used to generate new population. In this algorithm, the process of mutation is completed by randomly generating single gene positions and changing the gene. The specific operation process is shown in Figure 5.

Step 6 (iterative termination test). Determine whether to reach the maximum number of iterations. If so, go to Step 7; if not, Gen $=$ Gen +1 and go to Step 2 .

Step 7 (output results). It is the end.

\section{Numerical Experiment}

To verify the proposed model and algorithm, we design a numerical experiment of the rail-water transhipping terminal according to the Ningbo port. After analyzing the timetables of liner ships, the time in one cycle of planning is assumed as a week. Based on the data of the container liner ships arriving at peak time in a week, $2 \%$ of containers is supposed to be involved in rail-water intermodal transportation. During the planning cycle, there are 27 batches of containers leaving for four different directions. The original information of liner ships and containers is given in Table 1.
Considering the distribution of liner ship arrival time, 2 hours is assumed as a basic time-unit. There are 84 timeunits in the planning period from 18:00 on Sunday to the same time next Sunday. The time window of construction maintenance is 0:00-4:00 per day. There are total 1405 TEU, including the remaining 135 TEU from the previous cycle. The containers to direction 3 are more important because something is happening in direction 3 when the time is 46 . The importance coefficient $\eta_{j 3}^{T_{k}}=2\left(46 \leqslant T_{k} \leqslant 61\right)$ is set. The other importance coefficient is set to 1 .

According to the current standards of container-specific fixed-axle constraint and the limit of the loading line length, the number of containers on a train is defined between 70 TEU and 100 TEU. Given the analysis of the operating process in coordination area and the simplification of the problem, the average time of moving a container from the quay to the railway handling line is assumed as 2 timeunits, the average time of loading a container to liner train is assumed as 1 time-unit, and the storage capacity of the yard is assumed as 500 TEU.

Besides the objective function, there are other evaluation coefficients as follows, which can be used to analyze the comprehensive benefit of the container train distribution plan.

$N_{\text {yard }}^{\text {rest }}$ the total number of remaining containers during the planning cycle 
TABLE 1: Information of liner ships and containers in rail-water transhipping terminal.

\begin{tabular}{|c|c|c|c|c|c|}
\hline$i$ & $T_{i f}$ & $d=1$ & $d=2$ & $d=3$ & $d=4$ \\
\hline 0 & 0 & 20 & 40 & 30 & 45 \\
\hline 1 & 4 & 20 & 0 & 15 & 0 \\
\hline 2 & 7 & 15 & 0 & 15 & 10 \\
\hline 3 & 13 & 10 & 35 & 0 & 0 \\
\hline 4 & 19 & 0 & 0 & 20 & 25 \\
\hline 5 & 22 & 0 & 40 & 0 & 10 \\
\hline 6 & 25 & 25 & 0 & 0 & 15 \\
\hline 7 & 28 & 10 & 15 & 20 & 0 \\
\hline 8 & 30 & 0 & 20 & 15 & 15 \\
\hline 9 & 33 & 0 & 15 & 30 & 10 \\
\hline 10 & 37 & 25 & 0 & 15 & 10 \\
\hline 11 & 39 & 20 & 15 & 0 & 0 \\
\hline 12 & 41 & 0 & 15 & 35 & 0 \\
\hline 12 & 43 & 15 & 0 & 10 & 20 \\
\hline 14 & 44 & 0 & 0 & 25 & 0 \\
\hline 15 & 46 & 0 & 15 & 15 & 25 \\
\hline 16 & 48 & 10 & 0 & 30 & 0 \\
\hline 17 & 51 & 25 & 0 & 0 & 20 \\
\hline 18 & 53 & 25 & 0 & 15 & 20 \\
\hline 19 & 57 & 20 & 30 & 20 & 0 \\
\hline 20 & 59 & 20 & 30 & 0 & 15 \\
\hline 21 & 61 & 15 & 0 & 20 & 0 \\
\hline 22 & 64 & 0 & 20 & 0 & 20 \\
\hline 23 & 68 & 0 & 0 & 0 & 40 \\
\hline 24 & 73 & 35 & 25 & 0 & 0 \\
\hline 25 & 75 & 25 & 0 & 20 & 0 \\
\hline 26 & 79 & 30 & 0 & 0 & 35 \\
\hline 27 & 81 & 40 & 0 & 0 & 0 \\
\hline Total & 1405 & 405 & 315 & 350 & 335 \\
\hline
\end{tabular}

$N_{\text {yard }}^{\text {max }}$ the maximum number of containers in coordination area at the same time to evaluate the result of inbound container distribution organization

$\mathrm{NT}_{j}^{\mathrm{ave}}$ : the average container number on trains to describe train utilization rate and evaluate the efficiency of container trains.

4.1. Results of ICDOM. In this section, the performance of the GA is compared with the solution obtained via a fixed-axle departure method. The experiment is carried out by using MATLAB 2012 on an Intel Core i5, 3.60 GHz CPU, and 4 GB of RAM PC. The population size, crossover fraction, mutation rate, and GA generation are set at 100, 0.8, 0.2, and 300, respectively.

According to current standards of container-specific fixed-axle constraint and the limit of the loading line length, the number of containers on a train is set between $70 \mathrm{TEU}$ and 100 TEU. When fixed-axle constraint is set to 70 TEU and 100 TEU, there are 17 and 13 trains leaving the terminal, respectively. To compare the results of ICDOM with fixedaxle departure method, the number of trains is varied from
13 to 17 . However, when the number of trains is 17 , to fulfill the plan of opening 17 trains, it takes much more time to find the feasible solution rather than optimum one. Therefore, the result of 17 trains is excluded.

The optimized results produced by the ICDOM and GA and fixed-axle method are shown in Table 2 and Figure 6.

As shown in Figure 6, the total container-hours and total number of remaining containers are controlled with constraints.

When the number of container trains is 15 , the total container-hours in coordination area are 16110, the least of all. With the container trains amounts increasing from 13 to 15 , the total container-hours in coordination area decrease from 16645 to 16110 which is improved by $3.32 \%$ and the average number of containers on trains decreases from 89.5 to 86.5 . When the number of container trains increases to 16 , the total container-hours in coordination area increase to 16160. Because there is a large batch of containers arriving at the port when the train just leaves the port, longer concentration time makes the total container-hours in coordination area more than the one of 15 container trains. In addition, with the number of container trains going up, the total number 
TABLE 2: Evaluation results of container trains produced by the ICDOM and GA.

\begin{tabular}{lcccccc}
\hline Item & $n$ & $\mathrm{CH}_{\text {Cycle }}$ & $\mathrm{CH}_{\text {Cycle }}^{\text {ave }}$ & $N_{\text {yard }}^{\text {rest }}$ & $N_{\text {yard }}^{\text {max }}$ & NT $_{j}^{\text {ave }}$ \\
\hline ICDOM and GA & & & & & & \\
ICDOM 13 & 13 & 16645 & 11.85 & 240 & 310 & 89.5 \\
ICDOM 14 & 14 & 16290 & 11.59 & 200 & 285 & 86 \\
ICDOM 15 & 15 & 16110 & 11.47 & 110 & 325 & 86.5 \\
ICDOM 16 & 16 & 16160 & 11.49 & 60 & 255 & 84 \\
Fixed-axle & & & & & & \\
100 TEU & 13 & 19710 & 14.02 & 105 & 350 & 700 \\
70 TEU & 17 & 16810 & 11.96 & 130 & 270 & 75 \\
\hline
\end{tabular}

TABLE 3: Formation scheme of 15 container trains

\begin{tabular}{|c|c|c|c|c|c|c|c|c|c|c|c|c|c|c|c|}
\hline$j$ & 1 & 2 & 3 & 4 & 5 & 6 & 7 & 8 & 9 & 10 & 11 & 12 & 13 & 14 & 15 \\
\hline$T_{d j f}$ & 17 & 22 & 25 & 31 & 36 & 41 & 49 & 50 & 54 & 60 & 65 & 66 & 71 & 77 & 82 \\
\hline$d$ & 2 & 3 & 4 & 1 & 2 & 3 & 4 & 3 & 1 & 2 & 3 & 1 & 4 & 2 & 1 \\
\hline $\mathrm{NT}_{j}$ & 76 & 80 & 90 & 100 & 90 & 80 & 96 & 86 & 96 & 76 & 86 & 80 & 100 & 76 & 90 \\
\hline
\end{tabular}

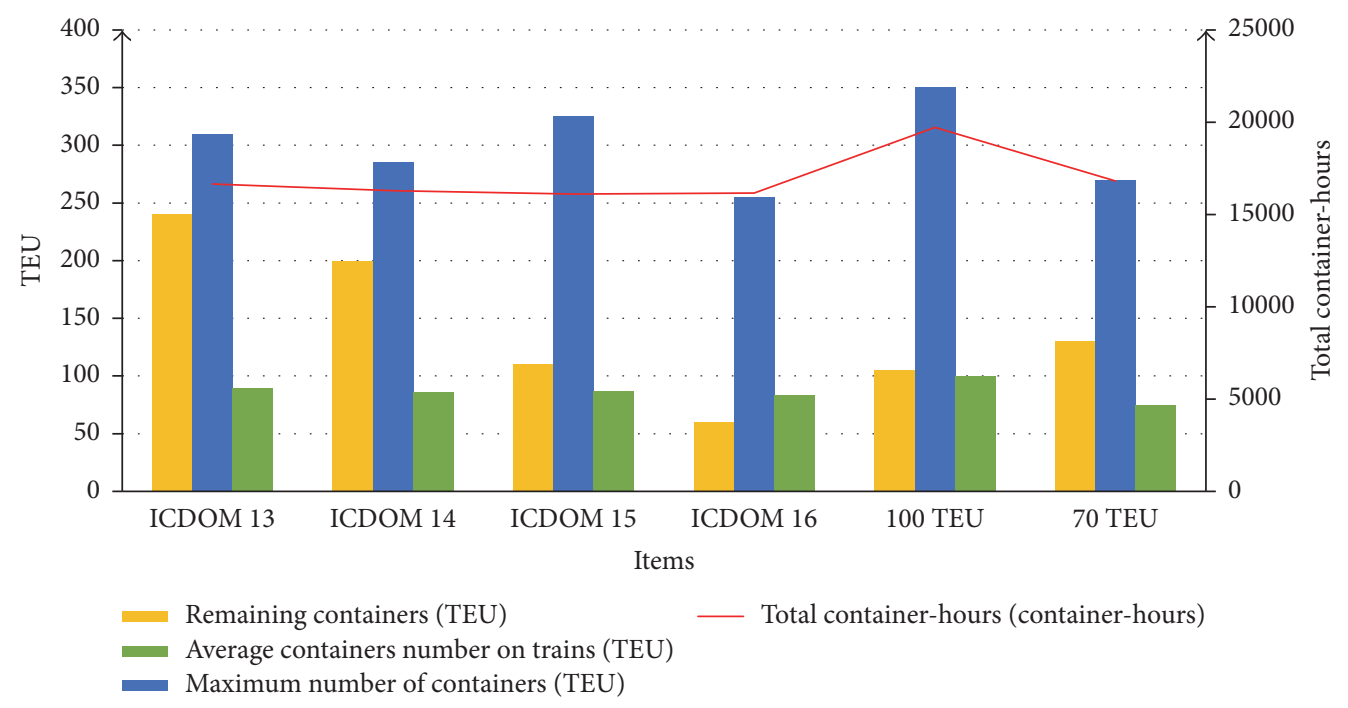

FIGURE 6: Evaluation results of container trains produced by the ICDOM and GA.

of remaining containers during the planning cycle decreases from 240 to 60 and the average container number on trains decreases from 89.5 to 94 .

In summary, the performance of the GA is effective. When the number of container trains is 15 , the total container-hours in coordination area reach the nadir, and the capacity of inbound container distribution arrives at the peak. It can be seen that the total container-hours of ICDOM and GA have been improved by up to $\mathbf{2 1 . 8 \%}$ when compared to that in fixed-axle method. The distribution organization scheme is shown in Table 3 , and the volume of containers in coordination area is shown in Figure 7.

4.2. Influence Factors Analysis. The influencing factors of the inbound container distribution organization are analyzed because different constraints during the numerical experiment may result in different solutions. The condition of 15 container trains is selected as the research object to investigate the influence of containers amounts on a train and the transhipping capacity in the coordination area. In this experiment, the minimum and maximum number of containers on a container train are changed from 30 TEU to 50 TEU and 110 TEU to 130 TEU, respectively. The minimum interval time of container transhipping is assumed as 1 timeunit from 2 time-unit. All settings are used to figure out their effects on the solutions, as shown in Table 4.

From Table 4, results of factors can be drawn.

(1) The results are the same as each other when the minimum number of containers is 30 and 40 and the maximum number of containers is 110 and 120 . On the one hand, the increasing maximum allowable number of containers leads to the higher average number of containers, which can reduce the total container-hours. On the other hand, the accumulation time increases due to more containers, 


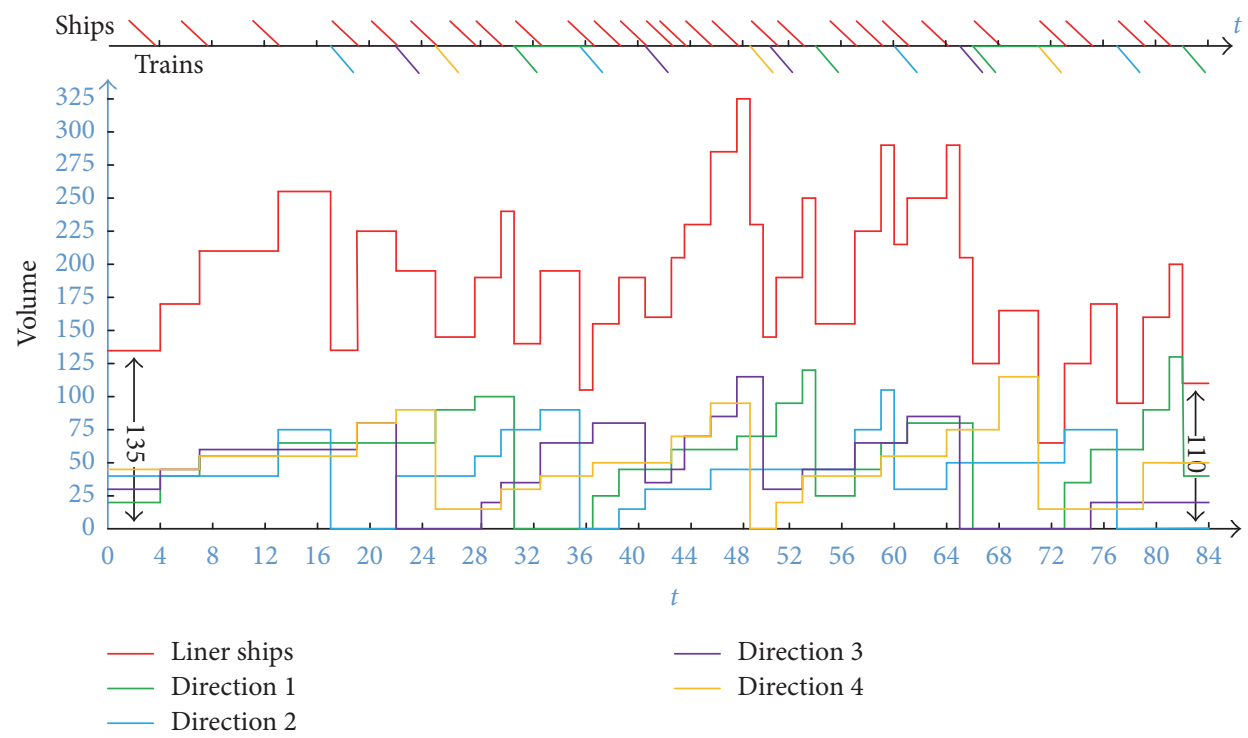

FIgURE 7: Transportation scheme and the volume of 15 container trains.

TABLE 4: Influence factors analysis of 15 container trains.

\begin{tabular}{|c|c|c|c|c|c|}
\hline Influence factors & $\mathrm{CH}_{\text {Cycle }}$ & $\mathrm{CH}_{\text {Cycle }}^{\text {ave }}$ & $N_{\text {yard }}^{\text {rest }}$ & $N_{\text {yard }}^{\max }$ & $\mathrm{NT}_{j}^{\mathrm{ave}}$ \\
\hline $\mathrm{NT}_{\min }=30, \mathrm{NT}_{\text {max }}=100, t_{\mathrm{trs}}=2$ & 15075 & 10.7 & 95 & 255 & 87.5 \\
\hline $\mathrm{NT}_{\min }=40, \mathrm{NT}_{\max }=100, t_{\mathrm{trs}}=2$ & 15075 & 10.7 & 95 & 285 & 87.5 \\
\hline $\mathrm{NT}_{\min }=50, \mathrm{NT}_{\max }=100, t_{\mathrm{trs}}=2$ & 15920 & 11.3 & 125 & 285 & 85.5 \\
\hline $\mathrm{NT}_{\min }=70, \mathrm{NT}_{\text {max }}=100, t_{\mathrm{trs}}=2$ & 16110 & 11.5 & 110 & 325 & 86.5 \\
\hline $\mathrm{NT}_{\min }=70, \mathrm{NT}_{\max }=110, t_{\mathrm{trs}}=2$ & 15175 & 10.8 & 135 & 270 & 84.5 \\
\hline $\mathrm{NT}_{\min }=70, \mathrm{NT}_{\max }=120, t_{\mathrm{trs}}=2$ & 15175 & 10.8 & 135 & 270 & 84.5 \\
\hline $\mathrm{NT}_{\min }=70, \mathrm{NT}_{\max }=130, t_{\mathrm{trs}}=2$ & 15020 & 10.7 & 175 & 315 & 82 \\
\hline $\mathrm{NT}_{\min }=70, \mathrm{NT}_{\max }=100, t_{\mathrm{trs}}=1$ & 15060 & 10.7 & 110 & 325 & 86.5 \\
\hline $\mathrm{NT}_{\min }=30, \mathrm{NT}_{\text {max }}=120, t_{\mathrm{trs}}=2$ & 13350 & 9.5 & 115 & 250 & 86 \\
\hline $\mathrm{NT}_{\min }=30, \mathrm{NT}_{\max }=120, t_{\mathrm{trs}}=1$ & 12675 & 9.0 & 160 & 210 & 83 \\
\hline
\end{tabular}

which results in the increasing total container-hours. Also, decreasing the minimum number could not change the results when it has already meet the satisfactory result.

(2) When the minimum number of containers on a container train reduces, the total container-hours and remaining containers in coordination area decrease. More specifically, the total container-hours decrease from 16110 to 15075 when the minimum number of containers on a container train decreases from 70 to 30 . When the maximum number of containers on a container train increases, the total containerhours decrease. In particular, the total container-hours decrease from 16110 to 15020 when the maximum number of containers on a container train increases from 100 to 120 . The minimum and maximum numbers of containers on a container train affect the results of distribution organization.

(3) When the minimum interval time of container transhipping is assumed as 1 time-unit, the total container-hours decrease to 15060 , but the other evaluation objects do not change. It proves that only speeding up the transhipping process is not a good option to increase the efficiency of distribution organization.

(4) When the limit of containers on a train is defined between 30 and 120, the total container-hours in coordination area rapidly drop down to 12675 , which means distribution organization capacity improves a lot.

\section{Conclusions}

The inbound container distribution organization with temporal and resource constraint in rail-water transhipping terminal is a complex system problem. In this paper, an effective two-point crossover GA is improved to deal with the ICDOM. The model and GA presented in this paper are applicable and easy to be implemented. In conclusion, the numerical experiment results show the following: (1) The model and algorithm are effective in optimizing inbound container distribution organization. (2) The number of the container trains and containers on a train should be set reasonably after 
the appropriate calculation. (3) Some constraints influence the efficiency of inbound container distribution organization, including the limits of containers on a train and the capacity of transhipping. And cooperative optimization is the best way to improve the efficiency.

Several improvements could be referred to for further research. Firstly, it would be interesting to investigate how the scale of the inbound container distribution organization would affect the results. Moreover, in actual distribution organization, liner ships or trains may disturb their schedules, so it is worth discussing how to adjust the organization.

\section{Conflicts of Interest}

The authors declare that there are no conflicts of interest regarding the publication of this paper.

\section{Acknowledgments}

This work is supported by the Major Program of National Natural Science Foundation of China under Grant 71390332, the Research Fund for the Doctoral Program of Higher Education of China under Grant 20130009110001, the Fundamental Research Funds for the Central Universities (2015JBM056), and Talented Faculty Funds of Beijing Jiaotong University (Grant no. 2016RC045).

\section{References}

[1] M. Janic, "An assessment of the performance of the European long intermodal freight trains (LIFTS)," Transportation Research Part A: Policy and Practice, vol. 42, no. 10, pp. 13261339, 2008.

[2] C. Macharis and Y. M. Bontekoning, "Opportunities for OR in intermodal freight transport research: a review," European Journal of Operational Research, vol. 153, no. 2, pp. 400-416, 2004.

[3] S. Wei, The Study of Container Multi-model Transportation Organizations Harmonized Plan Based on Coordination, Dalian Maritime University, 2007.

[4] Z. Qi, Theory research on the sea-rail combined container transport organization of the inland-port-transferring Railway Hub Container Transport System, Beijing Jiaotong University, 2004.

[5] L. Li, R. R. Negenborn, and B. De Schutter, "Intermodal freight transport planning - A receding horizon control approach," Transportation Research Part C: Emerging Technologies, vol. 60, pp. 77-95, 2015.

[6] V. Manish, V. Vedat, and Z. Nicolas, "A bi-objective model for planning and managing rail-truck intermodal transportation of hazardous materials," Transportation Research Part E: Logistics and Transportation Review, vol. 48, no. 1, pp. 132-149, 2012.

[7] M.-H. Phan and K. H. Kim, "Collaborative truck scheduling and appointments for trucking companies and container terminals," Transportation Research Part B: Methodological, vol. 86, pp. 3750, 2016.

[8] W. F. Wang and W. Y. Yun, "Scheduling for inland container truck and train transportation," International Journal of Production Economics, vol. 143, no. 2, pp. 349-356, 2013.
[9] H. Yan, Research on Several Problems in System Planning of Railway Container Transportation, Beijing Jiaotong University, 2008.

[10] J. Zhihong, L. Hui, S. Wei, and L. Na, "Graded optimization for multimodal container transportation planning," Journal of Shanghai Maritime University, vol. 31, no. 1, pp. 21-27, 2010.

[11] L. Qingsu, The optimization model and heuristic algorithm for scheduling problem of rail containerized cargoes in multimodal transportation, Beijing Jiaotong University, 2010.

[12] A. Kuo, E. Miller-Hooks, and H. S. Mahmassani, "Freight train scheduling with elastic demand," Transportation Research Part E: Logistics and Transportation Review, vol. 46, no. 6, pp. 10571070, 2010.

[13] S. Mu and M. Dessouky, "Scheduling freight trains traveling on complex networks," Transportation Research Part B: Methodological, vol. 45, no. 7, pp. 1103-1123, 2011.

[14] T. Yalong, Tang Yalong, The Operation Plan Research of Container Sea-Rail Intermodal Transportation Regular Train, Beijing Jiaotong University.

[15] H. Chen, K. Cullinane, and N. Liu, "Developing a model for measuring the resilience of a port-hinterland container transportation network," Transportation Research Part E: Logistics and Transportation Review, vol. 97, pp. 282-301, 2017.

[16] Y. Wu, J. Luo, D. Zhang, and M. Dong, "An integrated programming model for storage management and vehicle scheduling at container terminals," Research in Transportation Economics, vol. 42, no. 1, pp. 13-27, 2013.

[17] N. Li, G. Chen, K. Govindan, and Z. Jin, "Disruption management for truck appointment system at a container terminal: A green initiative," Transportation Research Part D: Transport and Environment, 2015.

[18] Q. Hu, X. Luan, F. Corman, and G. Lodewijks, "A Tabu Search Algorithm for Inter-terminal Container Transport," IFAC-PapersOnLine, vol. 49, no. 3, pp. 413-418, 2016.

[19] S. Hartmann, "Scheduling reefer mechanics at container terminals," Transportation Research Part E: Logistics and Transportation Review, vol. 51, no. 1, pp. 17-27, 2013.

[20] D. Ku and T. S. Arthanari, "Container relocation problem with time windows for container departure," European Journal of Operational Research, vol. 252, no. 3, pp. 1031-1039, 2016.

[21] Z. Wen, The coordination and optimization of transportation organization in hub station of container port and port and station on the basic of container rail-sea transportation, Southwest Jiaotong University, 2014.

[22] J.-W. Chung, S.-M. Oh, and I.-C. Choi, "A hybrid genetic algorithm for train sequencing in the Korean railway," Omega , vol. 37, no. 3, pp. 555-565, 2009.

[23] F. Zhao and X. G. Zeng, "Simulated annealing-genetic algorithm for transit network optimization," Journal of Computing in Civil Engineering, vol. 20, no. 1, pp. 57-68, 2006. 


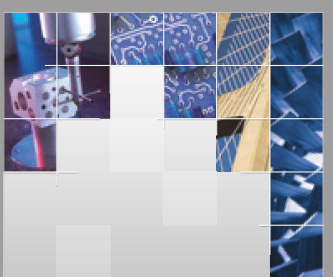

\section{Enfincering}
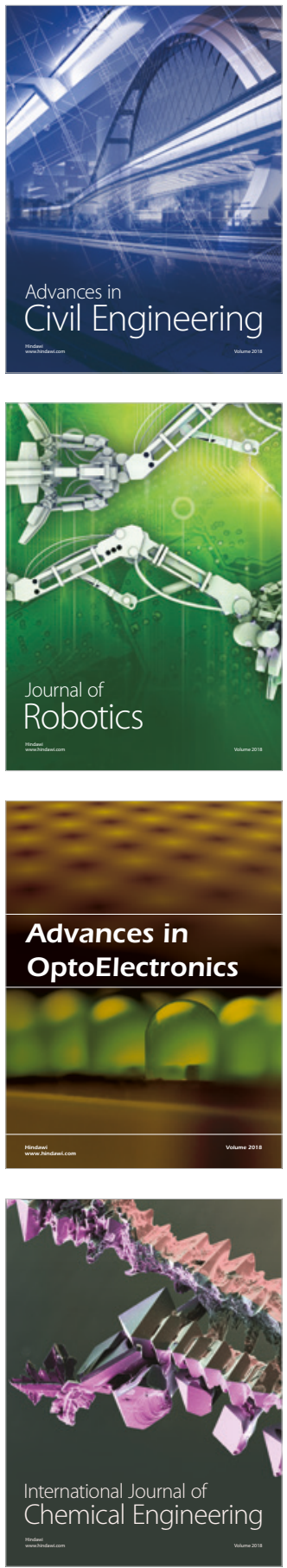

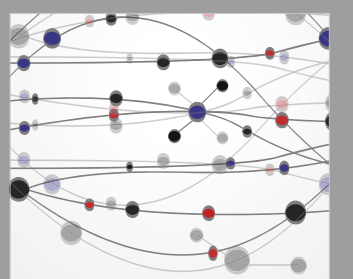

\section{Rotating \\ Machinery}

The Scientific World Journal

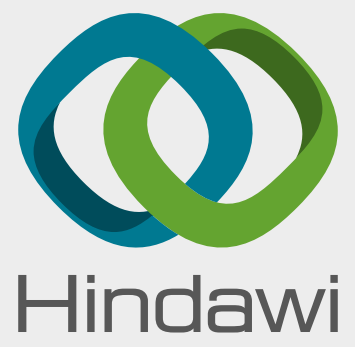

Submit your manuscripts at

www.hindawi.com
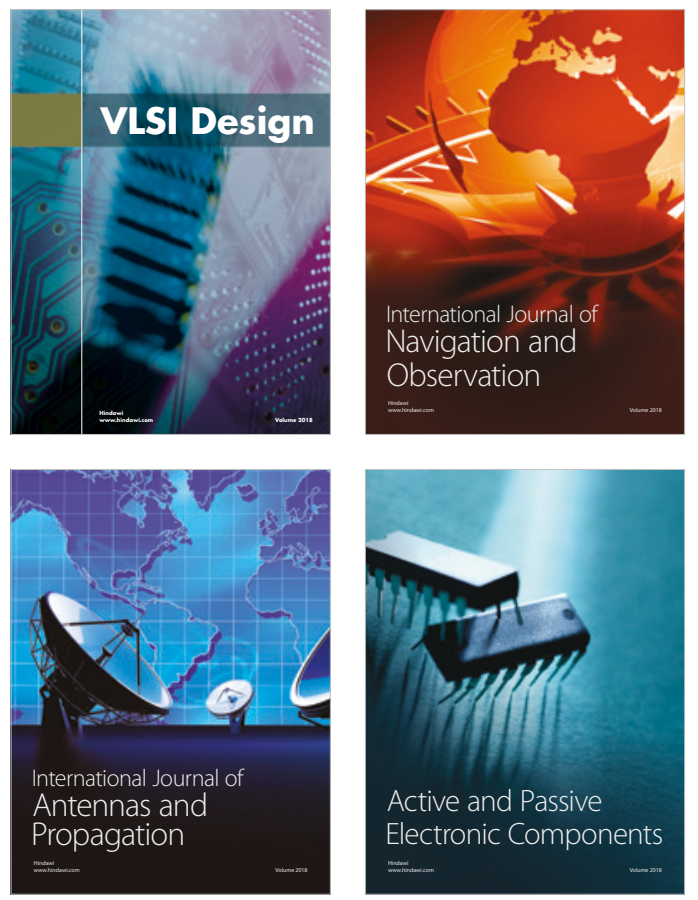
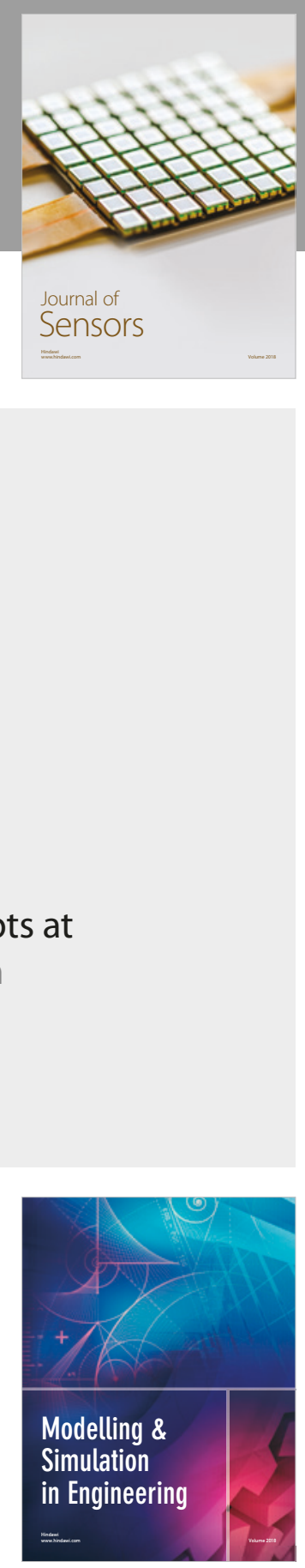

\section{Advances \\ Multimedia}
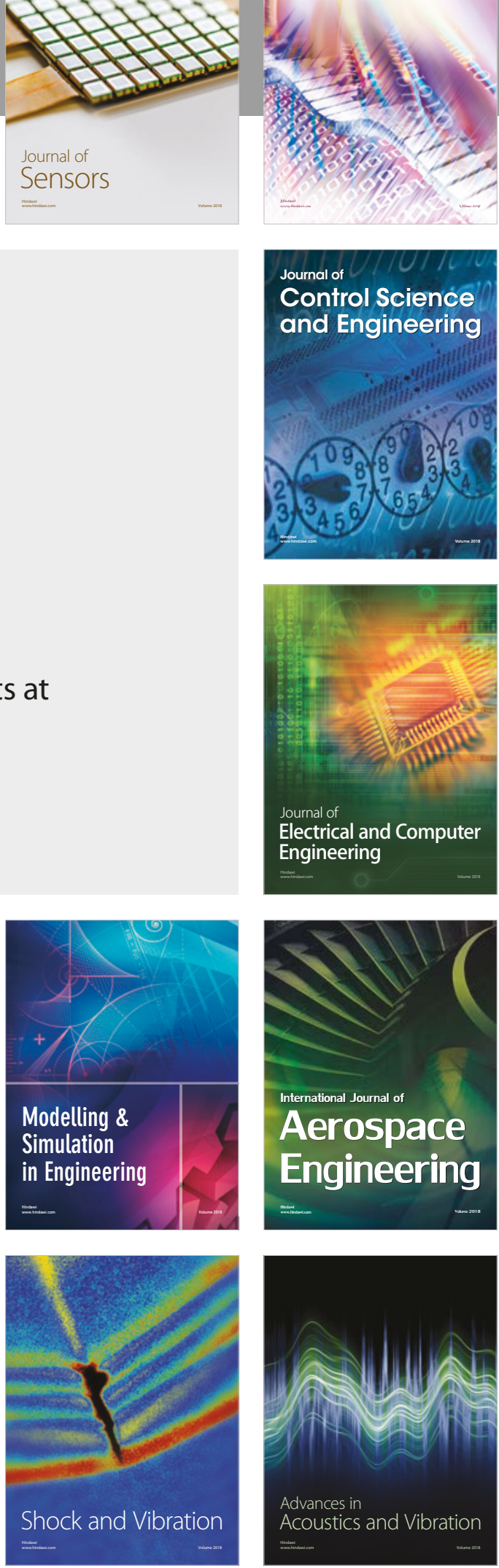